\title{
Studies on a Mutant Strain of Escherichia coli which Requires both Methionine and Lysine for Growth
}

\author{
By K. J. C. BACK AND E. G. WESTAWAY* \\ Department of Microbiology, University of Queensland, Brisbane, Australia
}

(Received 11 April 1961)

\section{SUMMARY}

A mutant of Escherichia coli was isolated which showed a requirement for methionine +lysine when a fairly large inoculum of washed organisms was used. Cystathionine or homocysteine replaced methionine, and diaminopimelic acid replaced lysine; no other amino acid or growth factor was active. The amounts of the amino acids required to promote growth were only about one-tenth of the quantity of methionine and lysine found in the grown organisms. A quantitative study with ${ }^{14} \mathrm{C}$-glucose and ${ }^{35} \mathrm{~S}$-sulphate confirmed that these amino acids were synthesized de novo. Although homoserine would not replace methionine for growth, the presence of unlabelled homoserine suppressed the incorporation of isotope from ${ }^{14} \mathrm{C}$-glucose into methionine and threonine, indicating that the accepted pathways are operative and that the block in methionine synthesis was in the formation of cystathionine. Small amounts of yeast extract replaced the amino acid requirement and decreased one-thousandfold the size of the inoculum required.

\section{INTRODUCTION}

Several reports suggest a relationship between the biosyntheses of methionine and lysine by bacteria. Davis $(1952 a, 1953)$ described mutants of Escherichia coli which, in the presence of traces of aspartic acid, showed an absolute requirement for $p$-hydroxybenzoic acid, which was satisfied by lysine + methionine, and it was suggested that $p$-hydroxybenzoic acid might therefore function in the synthesis of both these amino acids. Work (1955) reported the existence of several double mutants of $E$. coli which required lysine +methionine. Davis (1952b) described E. coli mutants, with a requirement for diaminopimelic acid or lysine or both, which accumulated threonine (derived from homoserine, a methionine precursor); another mutant utilized threonine as an alternative to diaminopimelic acid. The isolation by the present authors of a mutant of $E$. coli which requires methionine +lysine for growth prompted an investigation of the nature of the metabolic block, since existing information about the biosynthesis of these two compounds indicates no link or common precursor after aspartyl- $\beta$-semialdehyde (Fig. 1). This paper reports the results of a quantitative study of the nutrition of this mutant, by using ${ }^{14} \mathrm{C}$ and ${ }^{35} \mathrm{~S}-$ labelled compounds.

* Present address: Queensland Institute of Medical Research, Herston, Brisbane, Australia. 


\section{METHODS}

Organism. Escherichia coli substrain 15 is an auxotroph, derived by ultraviolet irradiation of wild-type $E$. coli 518 by the procedure of Adelberg \& Meyers (1953); the mutant exhibits a requirement for methionine +lysine. The mutant was maintained by monthly subculture on papain digest agar (Skerman, 1959) incubated at $37^{\circ}$ for $18 \mathrm{hr}$.

Inoculum. Organisms from an $18 \mathrm{hr}$. papain digest agar slope culture were suspended in sterile water at a concentration to give an absorption reading of 0.80

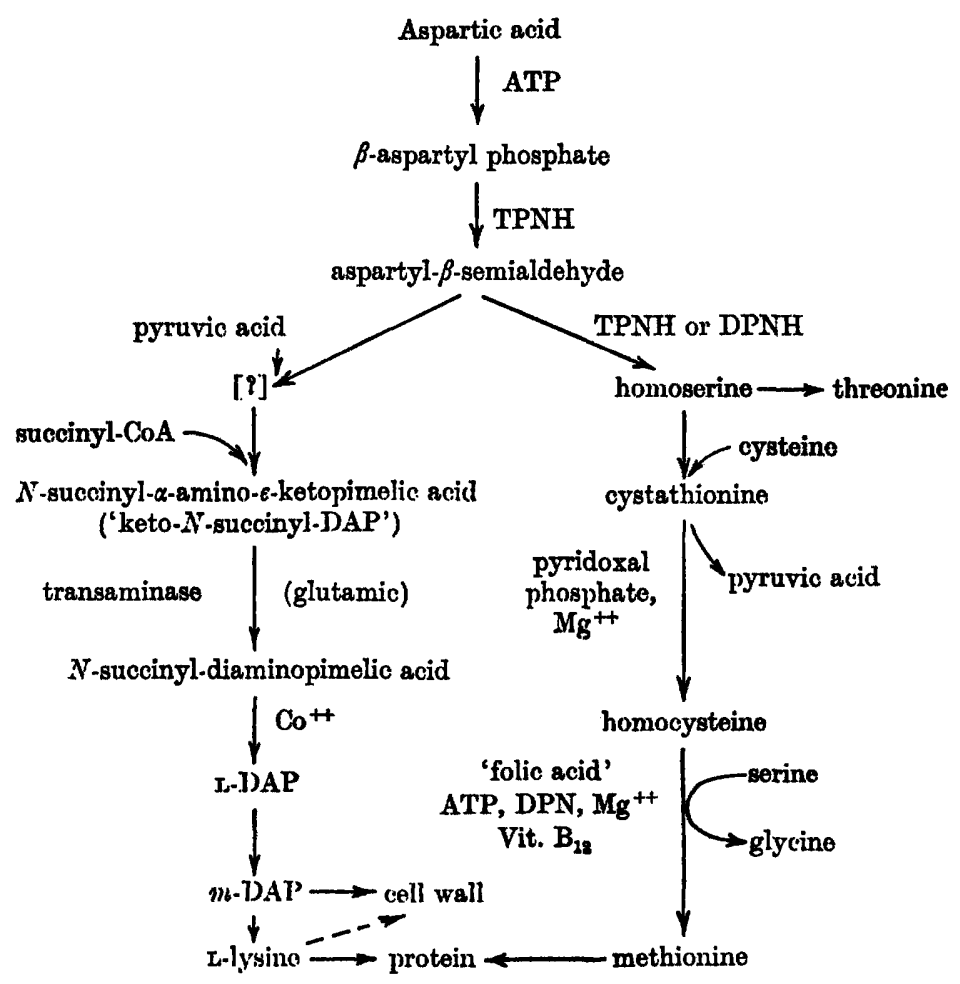

Fig. 1. The biosynthesis of methionine and lysine by bacteria (modifled from Gilvarg, 1960).

at $420 \mathrm{~m} \mu$ on the Unicam spectrophotometer Model SP600; the organisms were washed twice with sterile de-ionized water and resuspended to a concentration corresponding to an absorption reading of 0.20 (about $7 \times 10^{7}$ organisms $/ \mathrm{ml}$.). The short wavelength was chosen to permit accurate measurement of the relatively dilute suspensions used.

Growth tests. Growth tests were made in 'minimal medium C' containing $\mathbf{0 . 2} \%$ $(w / v)$ glucose (Roberts et al. 1955). The test medium was dispensed in 6 in. $\times \frac{8}{4}$ in. test tubes to give $4.0 \mathrm{ml}$. final volume and autoclaved at $115^{\circ}$ for $7 \mathrm{~min}$. Amino acid supplements (sterile solutions) and the inoculum $(10 \%, \mathrm{v} / \mathrm{v})$ were added after autoclaving. Tests, in duplicate, were incubated for $24 \mathrm{hr}$. at $37^{\circ}$ and the growth response recorded either qualitatively or by optical density measurement. The 
organisms in each tube were tested for viability and reversion by streaking a loopful on to minimal medium agar and papain digest agar and incubating for $24 \mathrm{hr}$. at $37^{\circ}$. Reversions were always to the prototroph, indicating that the double requirement was due to a single genetic block. For tests on solid medium, plates were prepared from a minimal medium containing washed agar $(2 \%, w / v)$ and inoculated with a $5 \%(\mathrm{v} / \mathrm{v})$ inoculum of the standard suspension described above. Growth supplements were supplied either by placing a small crystal of solid on the agar or by dipping a sterile 'fish-spine' bead (Bray's Interlocking Insulating Beads, Geo. Bray Co. Ltd., Leicester Place, Leeds, England; size no. 2) in $0.01 \mathrm{~m}$ solution and applying to the agar surface. Plates were incubated for $24 \mathrm{hr}$. at $37^{\circ}$.

Preparation of ${ }^{14} \mathrm{C}$ - and ${ }^{85} \mathrm{~S}$-labelled cell hydrolysates. Cultures $(50 \mathrm{ml}$.$) grown in$ minimal medium containing ${ }^{14} \mathrm{C}$-glucose $0.5 \mu \mathrm{c}$. $/ \mathrm{ml}$. or ${ }^{35} \mathrm{~S}-$ sulphate $0.3 \mu \mathrm{c} . / \mathrm{ml}$. (supplemented with minimal lysine and methionine in the case of the mutant) were harvested after incubation for $24 \mathrm{hr}$. at $37^{\circ}$ and washed in de-ionized water at $3000 \mathrm{~g}$ for $10 \mathrm{~min}$. until the washings were free from radioactivity. The organisms were suspended in $5 \mathrm{ml} .6 \mathrm{~N}-\mathrm{HCl}$ and hydrolysed by heating at $110^{\circ}$ for $16 \mathrm{hr}$. under nitrogen. The hydrolysates were filtered, washed, dried over solid $\mathrm{NaOH}$ in vacuo, redissolved, dried again and taken up in a measured volume of water. Amino-N was determined by the method of Moore \& Stein (1954).

Chromatography. Cell hydrolysates labelled with ${ }^{35} \mathrm{~S}$ were subjected to twodimensional paper chromatography without further treatment. Cell hydrolysates labelled with ${ }^{14} \mathrm{C}$ were fractionated in ion exchange columns into the basic amino acid fraction and the neutral + acidic amino acid fraction (Thompson, Morris \& Gering, 1959). The fractions were concentrated in vacuo and the amino- $\mathrm{N}$ content of each determined. Ammonia, which interferes with this determination, was removed by the addition of borate buffer in methanol to each sample for assay, which was then dried over $\mathrm{P}_{2} \mathrm{O}_{3}$ (Connell, Dixon \& Hanes, 1955).

Cell hydrolysates labelled with ${ }^{35} \mathrm{~S}$ and containing $100 \mu \mathrm{g}$. amino- $\mathrm{N}$, and the ${ }^{14} \mathrm{C}$-labelled neutral + acidic amino acid fraction containing $70 \mu \mathrm{g}$. amino-N, were applied to Whatman no. 1 paper $(27$ in. $\times 23$ in.), and methionine converted to the sulphoxide by the peroxide oxidation method of Thompson \& Morris (1959), except that 4 drops of $30 \%(w / v)$ hydrogen peroxide were used in a 4 in. watchglass and the paper exposed for $\mathbf{4 0} \mathrm{min}$. Two-dimensional descending paper chromatography was then used with $n$-butanol + glacial acetic acid +de-ionized water $(60+15+25$, by vol.) as the first solvent run across the grain, and phenol + deionized water $(4+1, v / v)$ as the second solvent (Smith, 1958). The leading edge of the paper for the run in the first dimension was cut to form $1 \mathrm{~cm}$. serrations and the solvent run for 48-64 hr. The second solvent was run until it almost reached the edge (24-30 hr.). For the separation of lysine, $0.2 \mathrm{ml}$. of the ${ }^{14} \mathrm{C}$-basic fraction containing 6-7 $\mu \mathrm{g}$. amino-N was applied as a strip $5 \mathrm{~cm}$. long along the base line of Whatman no. 1 paper (18 in. $\times 9$ in. with the leading edge serrated), and this was then developed along the grain in $n$-butanol + pyridine + de-ionized water $(1+1+1$, by vol.) for 58-72 $\mathrm{hr}$. (Morrison, 1958).

Assay of methionine and lysine eluted from chromatograms. The exact position of the amino acids on the chromatograms was defined by radioautography or by using detection ninhydrin spray (Connell et al. 1955). The located spots and an adjacent equal area free from amino acids were cut out and suspended from nichrome hooks 
in a vacuum desiccator. The papers were flooded with $0.28 \mathrm{ml}$. borate buffer in methanol (Connell et al. 1955) and dried over $\mathrm{P}_{2} \mathrm{O}_{8}$ in vacuo, thus removing ammonia. The dried papers were cut into $0.5 \mathrm{~cm}$. squares and eluted with $1.0 \mathrm{ml}$. de-ionized water. Standard quantities of lysine and methionine were chromatographed and eluted in the same way. The amino acid content of the eluates was then determined by the method of Moore \& Stein (1954).

Measurement of radioactivity. Samples of amino acid eluates described above were transferred quantitatively to $2 \mathrm{~cm} .^{2}$ brass planchets for radioactivity counts at infinite thinness. The planchets were prepared with a five degree inward slope on the floor of the well to offset surface tension effects at the periphery during drying. The sample (0.1 ml.) was carefully mixed on the planchet with 5 drops of an ethanolic suspension of purified asbestos powder as absorbent (Francis, Mulligan \& Wormall, 1954) and dried in vacuo over $\mathrm{P}_{2} \mathrm{O}_{5}$. The dried samples were counted with a thin mica end-window Geiger-Müller tube and Ekco scaler Type no. 529A. Under these conditions a ${ }^{14} \mathrm{C}$-source of activity $2.5 \times 10^{-3} \mu \mathrm{c}$. produced 610 counts $/ \mathrm{min} . \pm 1.5 \%$. Count rates of replicate planchets agreed within $5 \%$. Counts of duplicate planchets were taken for $10 \mathrm{~min}$.

\section{RESULTS}

\section{Growth responses on solid medium}

Medium C agar seeded with a $5 \%(\mathrm{v} / \mathrm{v})$ inoculum of the standard washed suspension described in Methods produced the best demonstration of the double requirement for lysine+methionine and was used for all growth tests in solid medium. A typical response after using this inoculum and incubating for $24 \mathrm{hr}$. at $87^{\circ}$ is shown in PI. 1, fig. 1. A smaller inoculum required prolonged incubation to demonstrate the response, whilst a larger inoculum produced too much background growth. In the presence of lysine the mutant responded to methionine, homocysteine, cystathionine; there was no response to homoserine, homoserine + cystine, threonine, DL- $\alpha$-aminobutyric acid, L-djenkolic acid or aspartic acid. In the presence of methionine the mutant responded to lysine and to diaminopimelic acid, but there was no response to lanthionine or to $\mathrm{DL}$-allo- $\delta$-(OH)-lysine.

There was no response by the mutant in minimal medium to $p$-aminobenzoic acid, $p$-hydroxybenzoic acid, ascorbic acid, biotin, folic acid, glutathione, D-pantothenic acid, pyridoxine, pyridoxal hydrochloride, nicotinic acid, thiamine hydrochloride or cobalamin. Yeast extract produced a good response when a $0 \cdot 1 \%(w / v)$ solution was applied in a 'fish-spine' bead.

\section{Growth responses in liquid medium}

The density of the inoculum had a marked effect on the type of growth response obtained in liquid medium (Table 1). With a heavy inoculum, growth occurred with lysine or methionine or both together, and sometimes in the absence of these supplements; with a dilute inoculum no growth occurred even in the presence of both amino acids. A 1/5 or 1/10 dilution of the standard washed suspension showed the double requirement. When, however, the sole supplement was Difco yeast extract $(0.2 \mathrm{mg} . / \mathrm{ml}$.) growth occurred even with high dilutions of the inoculum. Acid hydrolysis did not destroy the activity of yeast extract. 
Table 1. Growth responses of Escherichia coli 15 with different dilutions of a standard suspension as inoculum

Each 6 in. $\times \frac{7}{4}$. tube contained $4.0 \mathrm{ml}$. medium $\mathrm{C}$ supplemented as shown, the inoculum comprising $10 \%(v / v)$ of the final culture volume. The tubes were incubated for $24 \mathrm{hr}$. at $37^{\circ}$. Tests for viability: all tubes positive. Tests for reversions: all tubes negative. Hydrolysed yeast extract prepared by treating $10 \mathrm{mg}$. Difco yeast extract with $6 \mathrm{~N}-\mathrm{HCl}$ at $110^{\circ}$ for $16 \mathrm{hr}$. under nitrogen. After drying over $\mathrm{NaOH}$ the hydrolysate was dissolved in water and the culture medium supplemented so that each ml. medium contained hydrolysate from $\mathbf{0 . 2 5} \mathrm{mg}$. yeast extract.

Dilutions of the standard suspension used as inoculum

\begin{tabular}{|c|c|c|c|c|c|c|c|}
\hline \multirow[b]{2}{*}{ Supplements $\left(10^{-\mathbf{8}} \mathrm{M}\right)$} & \\
\hline & \multicolumn{7}{|c|}{ Growth response } \\
\hline None & $+1-$ & - & - & - & - & - & - \\
\hline Lysine & ++ & $+1-$ & - & - & - & - & - \\
\hline Methionine & ++ & - & - & - & - & - & - \\
\hline Lysine + methionine & ++ & $+t$ & ++ & $\begin{array}{l}+1- \\
\text { or }++\end{array}$ & - & - & - \\
\hline $\begin{array}{l}\text { Yeast extract }(0.2 \mathrm{mg} . / \mathrm{ml} .) \\
\text { Hydrolysed yeast extract }\end{array}$ & $\begin{array}{l}++ \\
++\end{array}$ & $\begin{array}{l}++ \\
++\end{array}$ & $\begin{array}{l}++ \\
+t\end{array}$ & $\begin{array}{l}++ \\
++\end{array}$ & $\begin{array}{l}++ \\
++\end{array}$ & $\begin{array}{l}++ \\
++\end{array}$ & $\begin{array}{l}++ \\
++\end{array}$ \\
\hline
\end{tabular}

Responses are indicated thus: $-=$ no visible growth; $+1-=$ faint growth; $++=$ full growth.

Table 2. Determination of the limiting amounts of lysine, diaminopimelic acid, and methionine required to support the growth of Escherichia coli 15

Experimental conditions as for Table 1 except that the inoculum throughout was $1 / 5$ dilution of the standard suspension. Tests for viability: all tubes positive. Tests for reversions: all tubes negative.

\begin{tabular}{|c|c|c|c|c|}
\hline Lysine & $\begin{array}{l}\text { Diamino- } \\
\text { pimelic acid } \\
\text { concentratio }\end{array}$ & $\begin{array}{l}\text { Methionine } \\
\text { (M) }\end{array}$ & $\begin{array}{r}\text { Total g } \\
\text { (duplicat } \\
\text { readi }\end{array}$ & $\begin{array}{l}\text { t } 24 \mathrm{hr} \text {. } \\
\text { bsorption } \\
0 \mathrm{~m} \mu \text { ) }\end{array}$ \\
\hline 一 & $\longrightarrow$ & 一 & 0 & 0 \\
\hline $10^{-\infty}$ & - & - & 0 & 0 \\
\hline- & $10^{-3}$ & 一 & 0.02 & $0.86^{*}$ \\
\hline - & - & $10^{-8}$ & 0 & 0 \\
\hline $10^{-5}$ & - & $8 \times 10^{-6}$ & 0.88 & 0.90 \\
\hline $8 \times 10^{-6}$ & - & $8 \times 10^{-6}$ & 0.07 & 0.90 \\
\hline $6 \times 10^{-6}$ & - & $8 \times 10^{-6}$ & 0.06 & 0.05 \\
\hline $4 \times 10^{-6}$ & - & $8 \times 10^{-6}$ & 0.05 & 0.04 \\
\hline $2 \times 10^{-8}$ & - & $8 \times 10^{-6}$ & 0.04 & 0.06 \\
\hline $10^{-6}$ & - & $8 \times 10^{-6}$ & 0.05 & 0.04 \\
\hline $10^{-5}$ & - & $8 \times 10^{-6}$ & 0.88 & 0.90 \\
\hline $10^{-5}$ & - & $6 \times 10^{-6}$ & 0.88 & 0.17 \\
\hline $10^{-5}$ & - & $4 \times 10^{-6}$ & 0.07 & 0.88 \\
\hline $10^{-5}$ & - & $10^{-6}$ & 0.88 & 0.04 \\
\hline- & $10^{-8}$ & $8 \times 10^{-6}$ & 0.86 & 0.86 \\
\hline - & $10^{-4}$ & $8 \times 10^{-6}$ & 0.86 & 0.86 \\
\hline - & $10^{-5}$ & $8 \times 10^{-6}$ & 0.06 & 0.08 \\
\hline 一 & $8 \times 10^{-6}$ & $8 \times 10^{-6}$ & 0.07 & 0.06 \\
\hline
\end{tabular}

* With $1 / 5$ inoculum dilutions, full growth occasionally developed in tubes supplemented with lysine or diaminopimelic acid only. 
Determination of the minimum amounts of lysine and methionine required to produce growth with a $1 / 5$ dilution of standard suspension as inoculum showed that only trace amounts were required (about $10^{-5} \mathrm{M}$ ) but the results became erratic in the vicinity of the 'end-point' (Table 2). An 'all or none' phenomenon was observed, there being either full growth or a faint trace of growth; intermediate amounts of growth were never observed. Similar results were obtained when diaminopimelic acid replaced lysine except that the requirement for diaminopimelic acid was higher than that for lysine.

\section{Quantitative investigation of amino acid synthesis by using ${ }^{14} \mathrm{C}-$ label}

Cell hydrolysates labelled with ${ }^{14} \mathrm{C}$ were prepared from the parentstrain Escherichia coli 518 and from the mutant $E$. coli 15 , and fractionated as described under Methods. The observation that homoserine did not replace methionine in growth tests suggested an isotopic competition experiment (Abelson, 1954) in which homoserine $(0.1 \mathrm{mg} . / \mathrm{ml}$.) was included in the culture medium of the mutant. The total yields of amino acids and recoveries from the fractionation procedure for the three hydrolysates are given in Table 3. The wild-type culture produced somewhat better growth than the mutant cultures; after hydrolysis of the organisms, and subsequent ion-exchange treatment, ninhydrin assays of the basic amino acid fractions and of the neutral + acidic amino acid fractions showed that 95-97\% of the amino-N originally present was recovered.

Table 3. Comparison of growth, amino nitrogen content and recoveries from the fractionation of ${ }^{14} \mathrm{C}$-labelled cell hydrolysates of Escherichia coli 518 and E. coli 15 Washed organisms were grown in $50 \mathrm{ml}$. medium $\mathrm{C}$ containing $25 \mu \mathrm{c}$. ${ }^{19} \mathrm{C}$-glucose (with
$8 \times 10^{-6} \mathrm{M}$ lysine $+4 \times 10^{-8} \mathrm{M}$ methionine supplements for $E$. coli 15). After harvesting
and hydrolysis of the organisms, the basic amino acids were separated on the ammonium
form of Dowex 50 resin. Amino- $N$ was determined by the ninhydrin method.

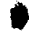

\section{Total growth}

Absorption at $420 \mathrm{~m} \mu$ of $1 / 10$ dilution of culture

Amino- $\mathbf{N}$ in cell hydrolysates $(\mu \mathrm{g}$.

Fractionation of hydrolysate

Amino-N treated ( $\mu \mathrm{g}$.)

Amino-N recovered in (B) fraction* ( $\mu$ g.)

Amino- $\mathbf{N}$ recovered in $(\mathbf{N}+\mathbf{A})$ fraction $\dagger$ ( $\mu \mathrm{g}$.

Total recovery of amino acids ( $\mu$ g.)

$\%$ recovery

\section{E. coli 518 \\ (wild-type)}

$\mathbf{0} \cdot \mathbf{1 7 5}$

1360

500

60

426

486

97
E. coli 15

with additional supplement of

homoserine

E. coli $15 \quad(0.1 \mathrm{mg} . / \mathrm{ml}$. $)$

$0 \cdot 150$

$\mathbf{0} \cdot 150$

1100

528

$71 \cdot 5$

485

$506 \cdot 5$

96

* (B) fraction represents 'basic amino acids'. $+(\mathrm{N}+\mathrm{A})$ fraction represents 'neutral + acidic amino acids'.

Radioautographs were prepared by exposing 'Kodirex No-Screen X-ray film' to the chromatograms of the various fractions for 80 days (Pl. 1, figs. 2-4). Comparison of the radioautographs of the neutral + acidic amino acid fractions of the hydrolysates showed that the amino acid pattern of the mutant (when grown in 
Table 4. Ninhydrin estimation and radioactivity counts of individual ${ }^{14} \mathrm{C}-$ amino acids in cell hydrolysates of Escherichia coli 518 and of E. coli 15

Washed organisms were grown in $50 \mathrm{ml}$. medium $\mathbf{C}$ containing $25 \mu \mathrm{c}$. ${ }^{10} \mathrm{C}$-glucose (with $8 \times 10^{-6} \mathrm{M}$ lysine $+4 \times 10^{-6} \mathrm{M}$ methionine supplements for $E$. coli 15 ), organisms hydrolysed and the hydrolysates fractionated on ion exchange columns. Basic amino acids (6 to $7 \mu \mathrm{g}$. amino-N) were separated by one dimensional, and neutral + acidic amino acids (70 $\mu \mathrm{g}$. amino-N) by two dimensional, paper chromatography.

E. coli 15 with additional supplement of

E. coli 518 (wild-type)

Amino-N in cell hydrolysates ( $\mu \mathrm{g}$. 14C-lysine

Lysine amino-N in eluate ( $\mu \mathrm{g} . / 100 \mu \mathrm{g}$. amino-N of cell hydrolysate)

Amino- $N$ in lysine supplement ( $\mu \mathrm{g}$.

Maximum dilution of isotope possible due to lysine supplement (\%)

Specific activity (as c.p.m./ $\mu$ g. amino-N)

14C-methionine

Eluate from chromatogram c.p.m.*

"C-threonine

Eluate from chromatogram c.p.m.
1860

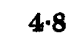

$$
0
$$

0

504

792

1308
E. coli 15

860

$5 \cdot 65$

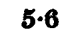

10

494

750

1380 homoserine

(0.1 mg./ml.)

1100

$$
\begin{aligned}
& \text { 5.8 } \\
& 5 \cdot 6 \\
& 9 \\
& 452 \\
& 380 \\
& \mathbf{3 3 0}
\end{aligned}
$$

* c.p.m. represents 'counts per minute' corrected for background.

minimal lysine + methionine) was similar to that of the wild-type, but differed markedly when homoserine was included in the growth medium, there being then a considerable decrease of radioactivity in methionine and threonine. Quantitative elution of methionine and threonine from the chromatogram followed by radioactive counts established this isotopic competition effect (Table 4). The addition of homoserine to the growth medium decreased the ${ }^{14} \mathrm{C}$-label in methionine by $56 \%$ and in threonine by $76 \%$. The decrease was less in the case of methionine because of the

Table 5. Comparison of growth, amino- $N$ content and radioactivity counts of

\begin{tabular}{|c|c|c|}
\hline & $\begin{array}{l}\text { E. coli } 518 \\
\text { (wild-type) }\end{array}$ & E. coli 15 \\
\hline Absorption reading at $420 \mathrm{~m} \mu$ of $1 / 10$ dilution of culture & $0 \cdot 195$ & $\mathbf{0} \cdot 150$ \\
\hline Amino-N in cell hydrolysates ( $\mu \mathrm{g})$. & 1750 & 1140 \\
\hline $\begin{array}{l}\text { Amino-N in eluates of }{ }^{25 S}-\text { methionine (sulphoxide, } \\
\mu \mathrm{g} . / 100 \mu \mathrm{g} \text {. amino-N of cell hydrolysate) }\end{array}$ & $\mathbf{2 \cdot 5 5}$ & $2 \cdot 45$ \\
\hline Amino-N in methionine supplement $(\mu \mathrm{g})$. & $\mathbf{0}$ & $\mathbf{2 \cdot 8}$ \\
\hline $\begin{array}{l}\text { Maximum dilution of isotope possible due to methionine } \\
\text { supplement (\%) }\end{array}$ & $\mathbf{0}$ & 10 \\
\hline $\begin{array}{l}\text { Specific activity of }{ }^{85} \mathrm{~S}-\text { methionine eluate (c.p.m./ } / \mu \mathrm{g} \text {. } \\
\text { amino-N) }\end{array}$ & $\mathbf{2 7 0 0}$ & 2620 \\
\hline Radioactivity of ${ }^{25}$ S-cystine/cysteic acid eluate (c.p.m.)* & 1750 & 1980 \\
\hline
\end{tabular}
${ }^{35}$ S-amino acids in cell hydrolysates of Escherichia coli 518 and of $\mathrm{E}$. coli 15

Washed organisms were grown in $50 \mathrm{ml}$. medium $\mathbf{C}$ containing $15 \mu \mathrm{c}$. ${ }^{\mathrm{s} S} \mathrm{~S}-\mathrm{sulphate}$ (with $8 \times 10^{-6} \mathrm{M}$ lysine $+4 \times 10^{-6} \mathrm{M}$ methionine supplements for $E$. coli 15 ). Organisms were harvested, washed and acid hydrolysed. ssS-Amino acids were separated by twodimensional paper chromatography. Quantity of hydrolysate chromatographed: $100 \mu$ g. amino-N. 
contribution of ${ }^{14} \mathrm{C}$ from cysteine and the $\beta$-carbon of serine. Lysine was examined for amino-N content and radioactivity from one-dimensional chromatograms of the basic amino acid fractions. Again it was found that the mutant and the wildtype organisms produced similar amounts of ${ }^{14} \mathrm{C}$-lysine, but no isotopic competition with homoserine was observed (Table 4).

\section{Quantitative investigation of amino acid synthesis by using ${ }^{35} \mathrm{~S}-$ label}

Hydrolysates of Escherichia coli 518 and $E$. coli 15 labelled with ${ }^{35} \mathrm{~S}$ supplied as ${ }^{35}$ S-sulphate were prepared, and the amino acids separated by two-dimensional paper chromatography. Because of the comparatively high specific activity of ${ }^{35}$ S-methionine, sufficient material was available in the eluate from each chromatogram to permit measurement of both radioactivity and amino- $\mathrm{N}$; the radioactivity of ${ }^{35} \mathrm{~S}$-cysteine was also measured. The results confirmed that the sulphur amino acid patterns of the mutant (grown in minimal lysine + methionine) and of the wildtype organisms were similar (Table 5).

\section{DISCUSSION}

Growth tests on solid medium showed a clear-cut response by Escherichia coli 15 to methionine +lysine, and one would therefore expect that the mutant had lost the ability to synthesize these amino acids. Replacement studies indicated that the methionine pathway was blocked at the condensation of homoserine and cysteine to form cystathionine and that the block in lysine biosynthesis occurred somewhere between aspartic acid and diaminopimelic acid. Quantitative studies of the growth of the organism in liquid medium, however, revealed that the situation was complex and that methionine and lysine produced growth in an indirect manner. This is illustrated by the following facts. First, the growth response to methionine + lysine was obtained only with a large inoculum $\left(10^{6}\right.$ organisms $/ \mathrm{ml}$.) irrespective of whether substrate amounts $\left(10^{-3} \mathrm{M}\right)$ or trace amounts $\left(10^{-5} \mathrm{M}\right)$ of the amino acids were used. Secondly, when yeast extract $(0 \cdot 2 \mathrm{mg} . / \mathrm{ml}$.) was the only supplement, the large inoculum was no longer required, a fact which indicated that the growth was not solely due to traces of methionine and lysine which may have been present in the yeast extract. Thirdly, the isotopic evidence showed that methionine and lysine were synthesized de novo by the mutant when trigger amounts of supplements were used with an inoculum of $10^{6}$ organisms $/ \mathrm{ml}$. The pronounced isotopic competition effect of unlabelled homoserine on the labelling of methionine and threonine indicated that these amino acids were synthesized by the accepted pathways (Fig. 1). The amounts of methionine and lysine found in the cell hydrolysates are in accord with those reported by other investigators (Roberts et al. 1955; Anderson et al. 1958). As methionine and lysine are stable metabolic end-products in $E$. coli (Abelson et al. 1953; Siddiqi, Kozloff, Putnam \& Evans, 1952), it follows that there was a true net synthesis and that exogenous methionine and lysine were incorporated unchanged.

It follows from these results that methionine and lysine in the medium were not functioning simply as cellular building materials but rather that they supplied a mechanism to overcome a metabolic block. The large inoculum required suggests that the organisms supplied a necessary component in this system. This requirement was spared by the incorporation of $0.2 \mathrm{mg} . / \mathrm{ml}$. yeast extract in the medium. The 
active principle in yeast extract does not appear to be an enzyme or a peptide, as its effect was unimpaired when tested subsequent to acid hydrolysis. If enzyme induction or repression is involved in the above system, then lysine and methionine per se would not appear to participate, because essentially identical growth responses occurred when these supplements were present from $10^{-3} \mathrm{M}$ to less than $10^{-5} \mathrm{M}$.

Although the available data do not provide an explanation of all the observed effects, they do suggest that a common link exists in the biosynthetic pathways leading to methionine and lysine. Such a link does not appear to be a common intermediate in view of the separation of the block in the methionine pathway from that of the lysine pathway. It is postulated that the link is a cofactor common to both pathways. The observation that the mutant did not respond to substrate amounts of lysine + methionine at less than $10^{\circ}$ organisms $/ \mathrm{ml}$. may mean that the cofactor participated also in some other undefined aspect of growth. It is hoped that a study of the growth components of the inoculum and of yeast extract will confirm the existence of a common link or cofactor and reveal both the nature of the metabolic block in Escherichia coli 15 and the mechanism developed to overcome this block.

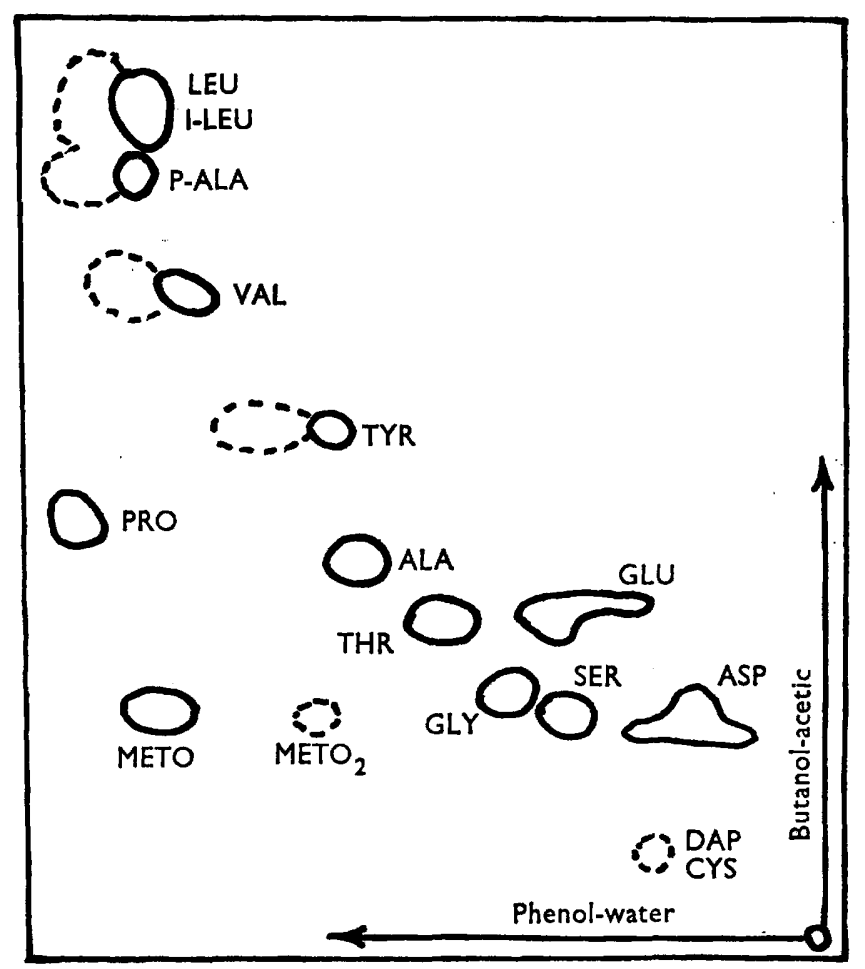

Fig. 2. Chromatographic map showing the location of amino acids on the radioautographs illustrated in P1. 1, figs. 2-4. The original chromatogram measured 27 in. $\times 28$ in. Abbreviations: LEU = leucine; I-LEU = isoleucine; P-ALA = phenylalanine; VAL $=$ valine $;$ PRO = proline; TYR = tyrosine; $\mathbf{A L A}=$ alanine $;$ THR $=$ threonine; GLU = glutamic acid, METO = methionine sulphoxide $; \mathrm{METO}_{2}=$ methionine sulphone; $\mathbf{G L Y}=$ glycine; $\mathbf{S E R}=$ serine; $\mathbf{A S P}=$ aspartic acid; $\mathbf{D A P}=$ diaminopimelic acid; CYS = cystine. 


\section{REFERENCES}

Abelson, P. H., Bolton, E., Britten, R., Cowie, D. B. \& Roberts, R. V. (1953). Synthesis of the aspartic and glutamic families of amino acids in Escherichia coli. Proc. nat. Acad. Sci., Wash. 39, 1020.

Aberson, P. H. (1954). Amino acid biosynthesis in Escherichia coli: Isotopic competition with "C-glucose. J. biol. Chem. 206, 335.

Adelberg, E. A. \& Meyers, J. W. (1953). Modification of the penicillin technique for the selection of auxotrophic bacteria. J. Bact. 65, 348.

Anderson, R. F., Rhodes, R. A., Nelson, G. E. N., Sherleton, M. C., Barreto, A. \& ARNowD, M. (1958). Lysine, methionine and tryptophan content of microorganisms. I. Bacteria. J. Bact. 76, 131.

Connele, G. E., Dixon, G. H. \& Hanes, C. S. (1955). Quantitative chromatographic methods for the study of enzymic transpeptidation reactions. Canad. J. Biochem. 33, 416.

Davis, B. D. (1952a). Aromatic biosynthesis. IV. Preferential conversion, in incompletely blocked mutants, of a common precursor of several metabolites. J. Bact. 64, 729.

Davis, B. D. (1952b). Biosynthetic interrelations of lysine, diaminopimelic acid and threonine in mutants of Escherichia coli. Nature, Lond. 169, 534.

Davis, B. D. (1958). Symposium on Microbial Metabolism. 5th Congr. int. Microbiol. p. 23.

Francis, G. E., Muluigan, W. \& Wormall, A. (1954). Isotopic Tracers. London: The Athlone Press.

Gilvarg, C. (1960). Biosynthesis of diaminopimelic acid. Fed. Proc. 19, 948.

Moore, S. \& StEIN, S. W. (1954). A modified ninhydrin reagent for the photometric determination of amino acids and related compounds. J. biol. Chem. 211, 907.

Morrison, R. I. (1953). The isolation of L-pipecolinic acid from Trifolium repens. Biochem. J. 53, 474.

Roberts, R. B., Abelson, P. H., Cowie, D. B., Bolton, E. T. \& Britten, R. J. (1955). Studies of biosynthesis in Escherichia coli. Publ. Carneg. Instn, no. 607.

Siddiqr, M. S. H., Kozloff, L. M., Putnam, F. W. \& Evans, E. A. (1952). Biochemical studies of virus reproduction. IX. Nature of the host cell contributions. J. biol. Chem. $199,165$.

Skerman, V. B. D. (1959). A Guide to the Identification of the Genera of Bacteria. Baltimore: Williams and Wilkins.

SMrт, I. (1958). Chromatographic Techniques. London: William Heinemann.

Thompson, F. J. \& Morris, C. J. (1959). Determination of amino acids from plants by paper chromatography. Analyt. Chem. 31, 1031.

Thompson, F. J., Morris, C. J. \& Gering, R. K. (1959). Purification of plant amino acids for paper chromatography. Analyt. Chem. 31, 1028.

Work, E. (1955). A Symposium on Amino Acid Metabolism, p. 462. Ed. by W. D. McElroy \& B. Glass. Baltimore: Johns Hopkins.

\section{EXPLANATION OF PLATE 1}

Fig. 1. Growth response of Escherichia coli 15 in medium $C$ agar. Supplements $\left(10^{-8} \mathrm{M}\right)$ applied in 'flsh-spine' beads and the plate was incubated at $37^{\circ}$ for $24 \mathrm{hr}$. $L=$ lysine; $M=$ methionine.

Fig. 2. Radioautograph of the ${ }^{14} \mathrm{C}$-labelled neutral + acidic amino acid fraction of the hydrolysed cells after two-dimensional chromatography. The hydrolysate was derived from Escherichia coli 518 (wild-type) grown in the presence of ${ }^{14} \mathrm{C}$-glucose. The amino acids may be identified by referring to Fig. 2, p. 9.

Fig. 3. Radioautograph obtained as in fig. 2, except that the hydrolysate was derived from $E$. coli 15 (mutant) grown in the presence of ${ }^{14} \mathrm{C}$-glucose and minimal lysine and methionine.

Fig. 4. Radioautograph obtained as in fig. 2, except that the hydrolysate was derived from $\boldsymbol{E}$. coli 15 (mutant) grown in the presence of ${ }^{14} \mathrm{C}$-glucose and minimal lysine and methionine + homoserine $(0.1 \mathrm{mg} . / \mathrm{ml}$.). Note the decrease in radioactivity of the methionine (sulphoxide) and threonine spots. 


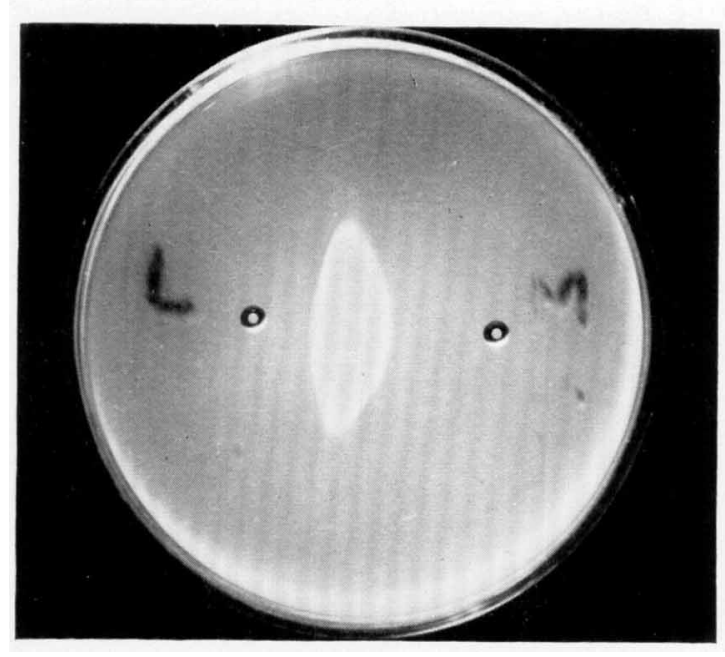

lig. 1

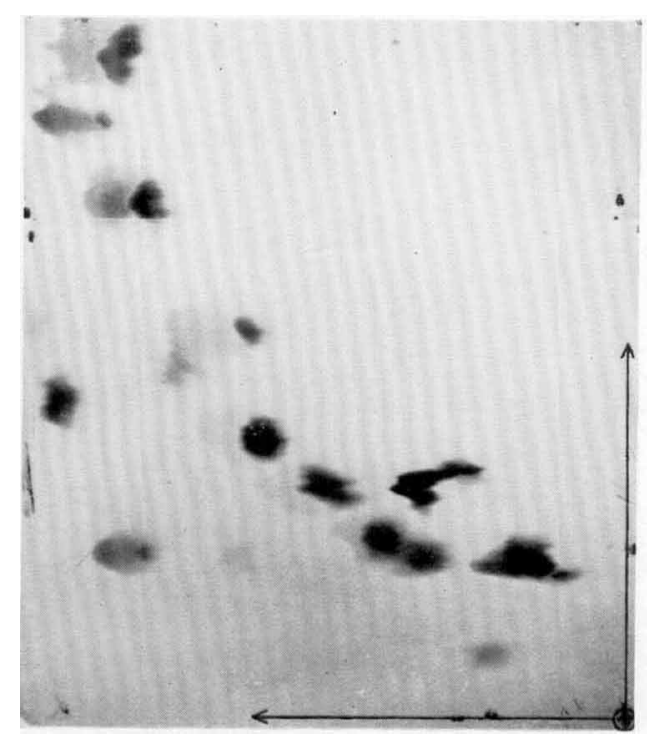

Fig. 3

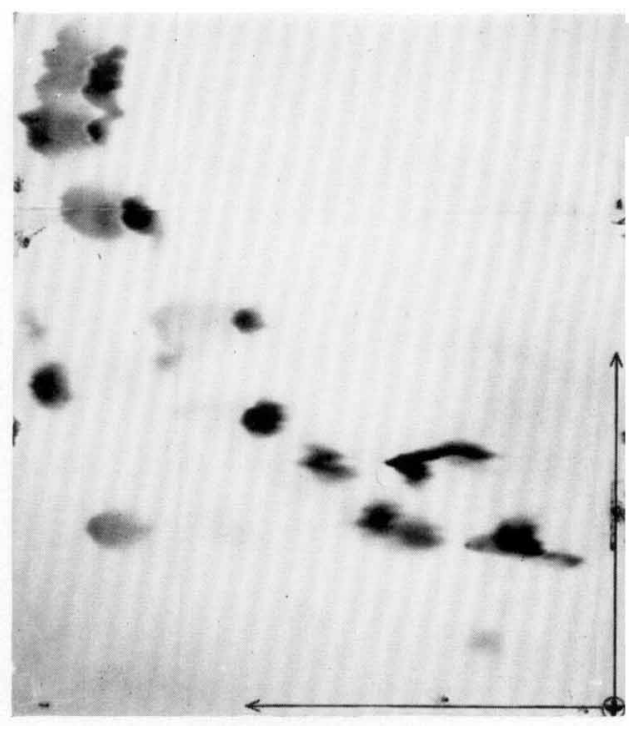

Fig. 2

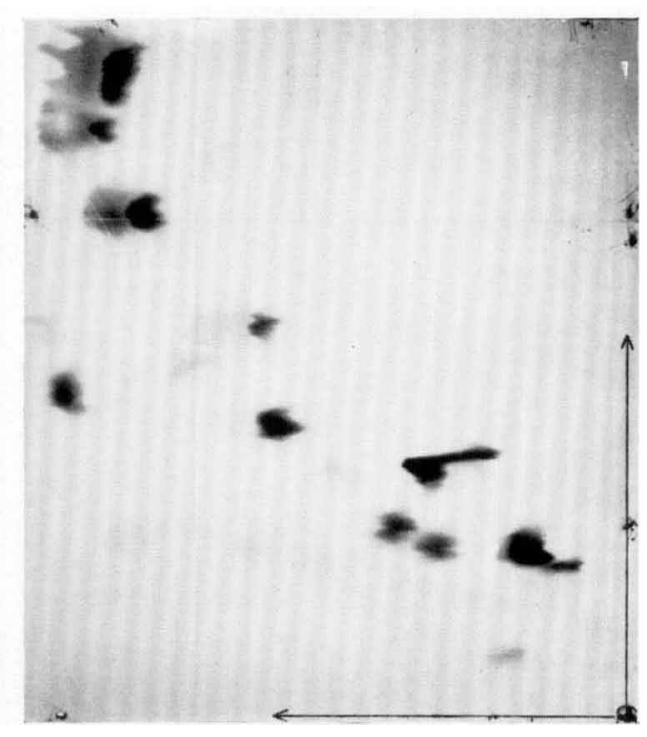

Fig. 4 